\title{
Chapter 5 Evolution of the French research reactor "fleet"
}

\subsection{The diversity and complementarity of French research reactors}

In the IAEA's Research Reactor Database (RRDB), 42 reactors in France are identified as being research reactors ${ }^{93}$ (including those no longer in operation, the Jules Horowitz reactor (JHR) which is under construction, and the research reactors at defence-related facilities $\left.{ }^{94}\right)$.

General de Gaulle created the French Atomic Energy Commission (CEA ${ }^{95}$ ) by decree in 1945, giving it responsibility for directing and coordinating the development of applications for the fission of the uranium atom nucleus. In this context, a team led by Lew Kowarski started up the first French research reactor in 1948, the ZOÉ atomic pile built at the CEA centre at Fontenay-aux-Roses (figure 5.1). The core of this reactor, consisting of uranium oxide-based fuel elements $(1,950 \mathrm{~kg})$ sitting in heavy water ( 5 tonnes) in an aluminium tank surrounded by a $90 \mathrm{~cm}$-thick graphite wall, stood within a 1.5 metrethick concrete containment wall designed to absorb the different types of ionizing radiation emitted by the nuclear reactions in the core. The ZOÉ reactor was used up to a power of $150 \mathrm{~kW}$ to study the behaviour of materials under irradiation, and at

93. This database gives the full list of French research reactors. See also the CEA publication entitled "Research Nuclear Reactors", a Nuclear Energy Division monograph - 2012, or the publication (in French) "Les réacteurs de recherche" by Francis Merchie, Encyclopédie de l'énergie, 2015.

94. This publication does not cover research reactors used for defence-related purposes.

95. Which would later become the Alternative Energies and Atomic Energy Commission. 


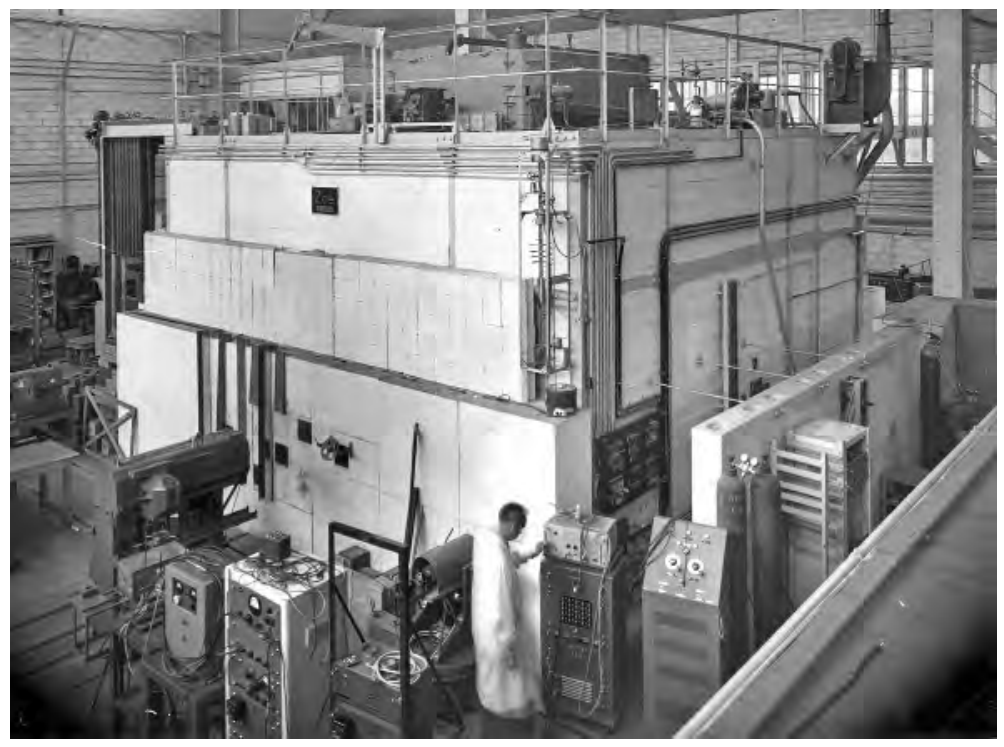

Figure 5.1. View of ZOÉ, France's first "atomic pile". CEA historic archives. @ CEA/Documentation service.

low power to characterize the neutronic properties of the materials used in atomic piles at the time (worldwide).

In the 1950s, some ten research reactors were commissioned in France. Having no industrial enrichment capability of its own at the time, France set about improving knowledge of the nuclear data for reactors using natural uranium. The AQUILON reactor at Saclay was designed for this purpose. This reactor and the ALIZÉ reactor (also at Saclay) were then used to support the design of the on-board reactors in the first French nuclear-powered submarines. The PROSERPINE reactor, also at Saclay, was used specifically for studying "homogeneous ${ }^{96}$ " reactors, using plutonium in solution as fissile material. PROSERPINE was light water-moderated. It was used to compare the neutron characteristics of two fundamental fissile elements: plutonium-239 and uranium-235.

In parallel during the 1950s, reactors were built for material testing and technological research. Thus the EL2 then the EL3 reactors were commissioned at Saclay for the purpose of producing artificial radioisotopes for studying the behaviour under irradiation of materials of structures used in reactors.

Towards the end of the 1950s, it became apparent that there was a need for better knowledge of the fundamental neutronics parameters involved in nuclear reactor core physics. In response to this need in particular, the MINERVE reactor was designed and commissioned in 1959 at the CEA centre at Fontenay-aux-Roses.

96. The fuel in a homogeneous reactor is in liquid form (nitrate or sulphate). 
A further twenty or so research reactors were commissioned in the 1960s. The development of the nuclear energy industry was already in full swing at the time but there were limited computing resources available. The use of critical assemblies or mockups $^{97}$ and material testing reactors appeared necessary to complete the acquisition of knowledge and data to support the industrial development of nuclear energy. France was attempting to develop the $\mathrm{GCR}^{98}$ (gas-cooled, graphite-moderated) reactor type using natural uranium as fuel. The MARIUS research reactor (commissioned in 1960 on the Marcoule site, then transferred in the mid-1960s to the CEA site at Cadarache) and the CESAR research reactor (commissioned in 1964 at Cadarache) were used in the early 1960s to conduct studies for the nuclear energy industry.

The use of fast neutron reactors was also explored at this time, especially for the purpose of using the plutonium resulting from the operation of the GCR reactors. The development of SFRs led in particular to the construction:

- of the HARMONIE reactor at Cadarache, which first went critical in 1965 and was used mainly to determine the neutron characteristics of radiological protection materials (the lateral neutron shielding around the core in fast neutron reactors);

- the MASURCA ${ }^{99}$ critical assembly, also situated at Cadarache and commissioned in 1966, which was used to study neutronics and, much later, to conduct research into the transmutation of the actinides present in highly radioactive nuclear waste.

The RAPSODIE reactor at Cadarache was the first fast neutron research reactor and ran on plutonium ${ }^{100}$ fuel and liquid sodium coolant. Numerous irradiation experiments were conducted in RAPSODIE between 1967 (the year of its first criticality) and 1982 (permanent shutdown in 1983), as part of the development of steel cladding for sodium-cooled fast neutron reactors (SFRs). Experiments known as "end-of-life testing", extending as far as the melting of fuel at the core of certain fuel rods, were conducted in 1982 (DISCO and FONDU tests).

The CABRI reactor, the first French reactor designed specifically for studying accident situations in SFRs (in a sodium loop), was built at Cadarache at the start of the 1960s; the first criticality of this reactor took place in December 1963. Tests were also carried out in the sodium loop to study accident situations in pressurized water reactors (tests known as REP-Na). The SCARABEE reactor, used in the 1980s for tests related to sodium-cooled fast neutron reactors (since shut down and dismantled), shared the main equipment of the CABRI reactor. It had a sodium loop of larger diameter than the one used in the CABRI reactor.

The willingness of the USA to supply highly enriched fuel with uranium-235 meant that it was possible in the 1960s to design higher power reactor cores with more intense

97. Reactors using fuel element arrangements representative of the cores being studied ("assembly") and operating at almost zero power ("just critical").

98. UNGG (Uranium Naturel Graphite-Gaz) in French.

99. Breeding assembly at the Cadarache Research Centre.

100. The RAPSODIE reactor, like subsequent French SFRs, ran on mixed $\cup_{2}-\mathrm{PuO}_{2}$ fuel; axial and radial "blankets" of uranium-238 (depleted uranium), a fertile material under a fast neutron flux, were also placed around the fissile zone. 
neutron fluxes, so the reactors could be used for material testing. In France, three material testing reactors were designed at this time: the $30 \mathrm{MW}$ PEGASE reactor at Cadarache, the $35 \mathrm{MW}$ SILOE reactor at Grenoble (forced downstream water circulation; this reactor was in operation from 1963 to 1997), and the 70 MW OSIRIS reactor (figure 5.2) at Saclay (upstream water circulation; in operation from 1966 to 2015). These reactors were each accompanied by a critical assembly: PEGGY for PEGASE, SILOETTE (figure 5.2) for SILOE and ISIS for OSIRIS.
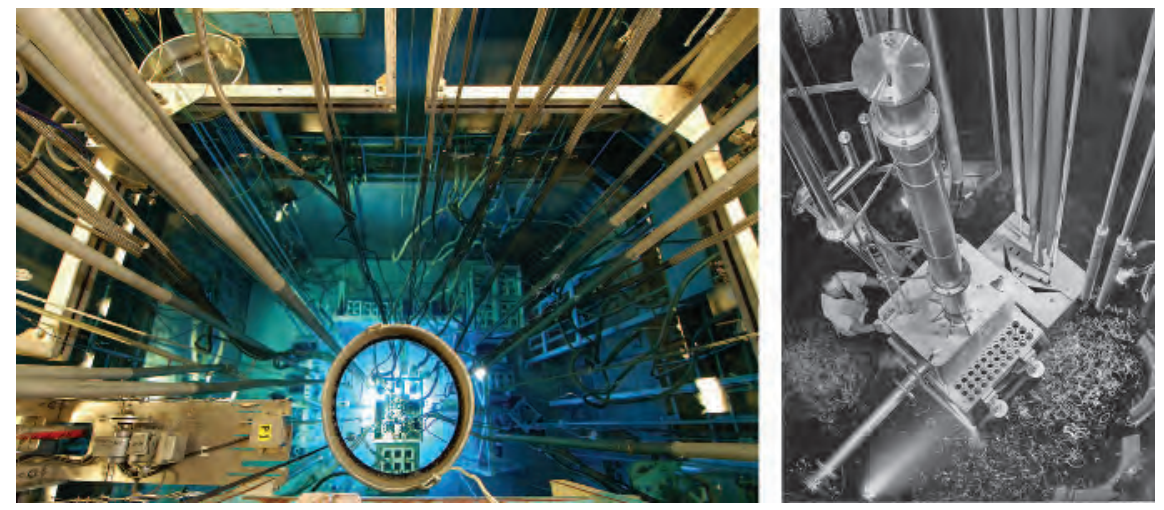

Figure 5.2. Left, Osiris reactor core. View of the submerged neutron radiography installation (2004). (c) L. Godart/CEA; right, view of the SILOETTE critical assembly. @ CEA.

Unlike the high flux reactor $\left(\mathrm{RHF}^{101}\right)$ in Grenoble and the ORPHEE reactor, SILOE was a light water pool-type reactor built for irradiating materials and equipment. The core (figure 5.3) consisted of elements containing fuel enriched to $90 \%$ uranium- 235 .

However, the SILOE reactor also had neutron channels not aimed directly at the core, as well as a beryllium ${ }^{102}$ wall along one of the four sides of the core ${ }^{103}$. To start with, there were only two radial channels. After the MELUSINE reactor was shut down in 1988, a tangential channel was added to SILOE, which aimed at the beryllium wall through the slice. This brought the number of instruments to six, with two devices per channel (spectrometers, diffraction meters). Despite difficult working conditions for the scientists (high temperatures, confined spaces, etc.), this equipment gave excellent service from a scientific point of view and was used to train scientists, especially in powder diffraction and single crystal diffraction, as well as polarised neutron scattering.

In 1969, France took the decision to stop building GCR reactors in favour of USdesigned pressurized water reactors. In the decade that followed, with experimental

101. Réacteur à Haut Flux in French.

102. This material is a neutron source when struck by high energy gamma rays in particular.

103. Source: ARILL ("Association des retraités de l'Institut Laue-Langevin"): "Le réacteur de recherche Siloé". 


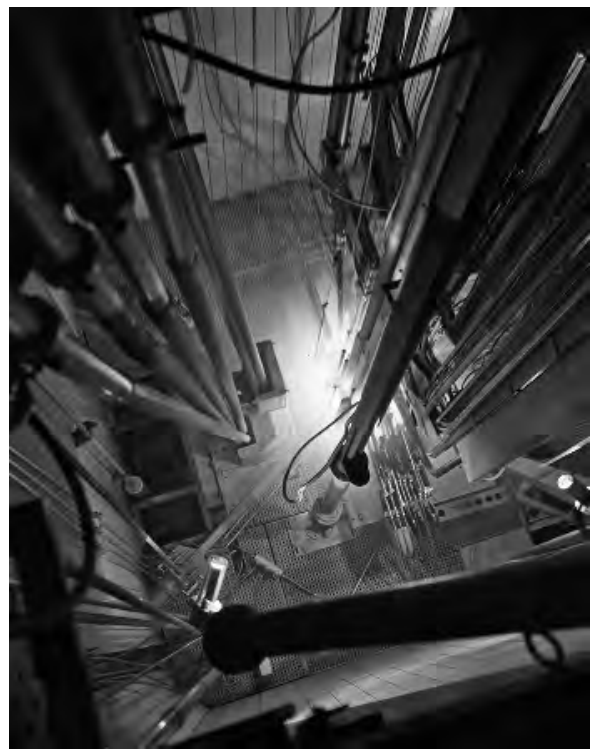

Figure 5.3. View of the SILOE reactor core. @ CEA.

needs largely being met, few new research reactors were built compared to the 19501970 period.

However, two high flux reactors, with neutron beams for fundamental physics experiments, were then commissioned: the high flux reactor (the $58 \mathrm{MW} \mathrm{RHF)} \mathrm{at}$ Grenoble, run by the Institut Laue-Langevin (ILL), which went critical in 1971, and the ORPHEE reactor (14 MW) at Saclay, which went critical at the end of 1980.

In 1972, in association with EDF, the CEA set up the Pile Construction Department within the Atomic Piles Division at the CEA. The Department was subsequently hived off and attached to the company Technicatome ${ }^{104}$, which would become the TA branch of the company AREVA. These entities and companies made a major contribution to the design and construction of research reactors, up to and including the Jules Horowitz reactor.

As regards the development of fast neutron reactors, a large number of experimental irradiations were carried out in the PHENIX power reactor, at Marcoule, which was commissioned in 1974, until its final shutdown in February 2010. As was the case with the RAPSODIE reactor, later tests also known as "end-of-life ${ }^{105 "}$ tests related to safety issues were carried out (e.g. the possibility of initiating natural convection of the sodium in different reactor circuits, the risk of cladding failure in the event of partial melting in the core of a pin containing fuel pellets, etc.).

104. The company GAAA (Groupement Atomique Alsacienne Atlantique), which later became Novatome, worked with the CEA and EDF on the design of the fast neutron reactors.

105. See the publication by Joël Guidez "PHENIX - The experience feedback", Chapter XV, Collection: Hors Collection, EDP sciences, 2013. 
Similarly, the PHEBUS test reactor was commissioned in 1978 at Cadarache to study cooling accidents in pressurized water reactors.

Finally, the CEA launched a project to build a new material testing reactor, the Jules Horowitz reactor. The reactor, which is under construction at Cadarache, will take over from the OSIRIS reactor, the final shutdown of which took place at the end of 2015 . We will look at this new reactor in more detail later on.

Table 5.1 below presents the French reactors used either wholly or partially for experiments, with their commissioning date (excluding facilities used for defence purposes).

Table 5.1. List of French reactors used wholly or partially for experiments, with their commissioning date.

\begin{tabular}{|c|c|c|c|c|}
\hline $\begin{array}{l}\text { Reactor } \\
\text { type } \rightarrow \\
\text { uses } \\
\downarrow\end{array}$ & $\begin{array}{l}\text { Reactors using } \\
\text { (light or heavy) } \\
\text { water or air for } \\
\text { core cooling }\end{array}$ & $\begin{array}{l}\text { Reactors } \\
\text { using liquid } \\
\text { sodium for } \\
\text { core cooling }\end{array}$ & $\begin{array}{l}\text { Critical } \\
\text { assemblies }\end{array}$ & $\begin{array}{l}\text { Neutron beam } \\
\text { reactors (heavy } \\
\text { water/light } \\
\text { water) }\end{array}$ \\
\hline $\begin{array}{l}\text { Studies of } \\
\text { reactor } \\
\text { physics } \\
\text { (including the } \\
\text { determination } \\
\text { of nuclear } \\
\text { data), } \\
\text { radiological } \\
\text { protection, } \\
\text { irradiation }\end{array}$ & $\begin{array}{l}\text { ZOE (1948) } \\
\text { EL2 (1952) } \\
\text { EL3 (1957) } \\
\text { MELUSINE (1959) } \\
\text { TRITON (1959) } \\
\text { NEREIDE (1960) } \\
\text { PEGASE (1963) } \\
\text { SILOE (1963) } \\
\text { OSIRIS (1966) } \\
\text { JHR (under } \\
\text { construction) }\end{array}$ & $\begin{array}{l}\text { RAPSODIE (1966) } \\
\text { PHENIX (1974) }\end{array}$ & $\begin{array}{l}\text { AQUILON (1956) } \\
\text { PROSERPINE (1958) } \\
\text { ALIZE (1959) } \\
\text { RUBEOLE (1959) } \\
\text { MINERVE (1959) } \\
\text { MARIUS (1960) } \\
\text { PEGGY (1961) } \\
\text { RACHEL (1961) } \\
\text { SILOETTE (1964) } \\
\text { CESAR (1964) } \\
\text { EOLE (1965) } \\
\text { ISIS (1966) } \\
\text { HARMONIE (1965) } \\
\text { MASURCA (1966) }\end{array}$ & \\
\hline Safety tests & $\begin{array}{l}\text { CABRI (sodium loop, } \\
\text { 1972) } \\
\text { PHEBUS (1978) } \\
\text { CABRI (water loop) }\end{array}$ & $\begin{array}{l}\text { RAPSODIE (1966) } \\
\text { PHENIX (1973) } \\
\text { (for "end-of-life" } \\
\text { tests) }\end{array}$ & & \\
\hline $\begin{array}{l}\text { Studies of the } \\
\text { physics of } \\
\text { matter }\end{array}$ & & & & $\begin{array}{l}\text { RHF (1971) } \\
\text { ORPHEE (1980) }\end{array}$ \\
\hline Teaching & $\begin{array}{l}\text { MINERVE (1959) } \\
\text { ULYSSE (1961) } \\
\text { Argonaut class } \\
\text { SILOETTE (1964) } \\
\text { RUS « Cronenbourg » } \\
\text { (1966) } \\
\text { Argonaut class } \\
\text { ISIS (1966) }\end{array}$ & & & \\
\hline
\end{tabular}




\subsection{Current situation}

Since the ZOÉ pile, around forty research reactors have therefore been built and operated in France. In mid-2018, with the shutdown of the OSIRIS reactor, there were seven research reactors left "in operation"106. The others are scheduled for permanent shutdown without utilization (PHEBUS), are decommissioned or dismantled, or have already been dismantled.

Of the reactors still in operation, three are critical assemblies: EOLE, MINERVE and MASURCA, now all at Cadarache. The MINERVE reactor (figure 5.4) was commissioned in 1959 at the Fontenay-aux-Roses centre but was transferred to Cadarache in 1977. It is dedicated to the neutron characterization of materials (fissile, fertile, neutron-absorbing or structural materials) and to studying the physics of cores of different types of reactor. It is a pool-type reactor with a maximum operational power of $100 \mathrm{~W}$. The reactor core, which consists of fuel elements in the form of UAl alloy plates, enriched to around $93 \%$ uranium-235, is surrounded by graphite reflector elements and submerged in a large volume of demineralized water $\left(140 \mathrm{~m}^{3}\right)$, which protects the operators from ionizing radiation and removes the (small amount of) heat from the core.

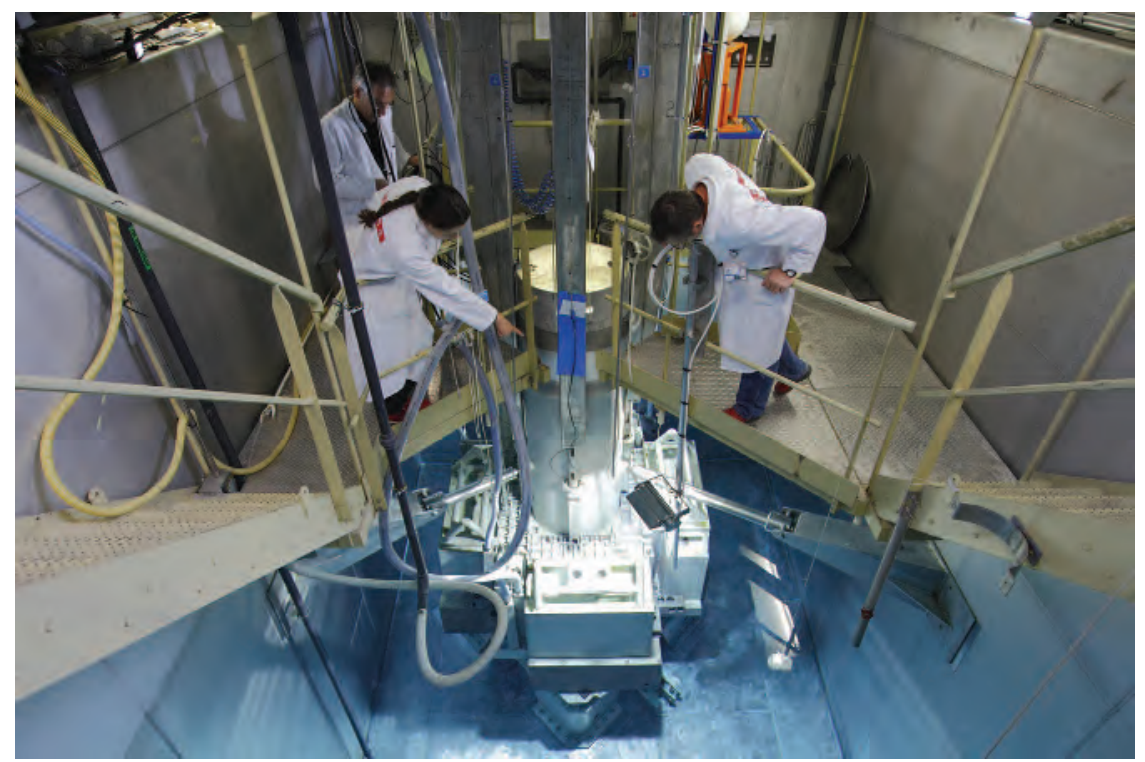

Figure 5.4. The MINERVE pool. Loading a sample into the central cavity to measure the reactivity effect using the "oscillation method". @ G. Lesénéchal/CEA.

The EOLE reactor (figure 5.5), commissioned in 1965, is in the same building as the MINERVE reactor. It also operates at very low power (100 W maximum), but its design is very different to that of the MINERVE reactor. The EOLE reactor, which has a variety

106. ORPHEE, ISIS, MASURCA, CABRI, EOLE, MINERVE and the RHF. 


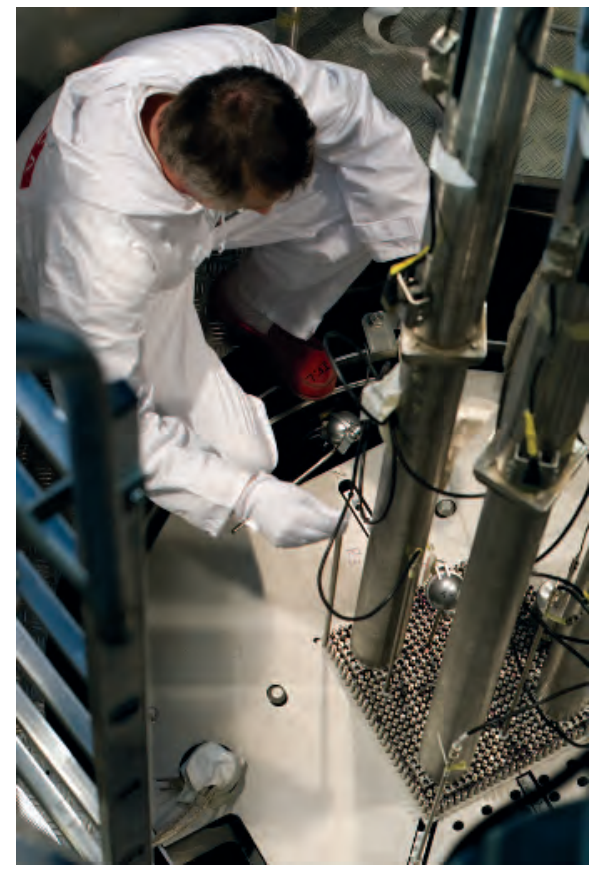

Figure 5.5. View of the EOLE reactor vessel configured for the PERLE experiment (2008). C P. Dumas/CEA.

of measuring equipment ( $\gamma$ spectrometry, fission chambers, thermoluminescent detectors), can entirely characterize core configurations from a physics and neutronics point of view. During every experimental programme conducted in the EOLE reactor, a new core is loaded using the facility's available fuel elements. The core is placed in a small metal vessel (around 1 metre high by 1 metre in diameter) into which water, maintained at a consistent temperature and possibly borated, is gradually injected until criticality is reached. Measurements are then carried out on the fuel elements not only while it is at power but also once the reactor has been shut down. By repeating these measurements for different experimental core configurations (change of material, replacement of a fuel element by water, insertion of an experimental device, etc.), it is possible not only to characterize the effects of the tested materials and devices on core reactivity, but also to assess characteristic neutronics parameters such as the Doppler effect or the effect of the moderator (neutron feedback). The EOLE reactor, for example, played a part in the qualification of neutronics modelling tools used to design the Jules Horowitz research reactor (JHR).

The MASURCA critical assembly (figure 5.6), also at Cadarache, has the particular characteristic of being cooled not by water but by air. The experimental cores loaded into it are much bigger (up to $6 \mathrm{~m}^{3}$ in volume) than those that can be loaded into the EOLE and MINERVE reactors. The MASURCA assembly, which has a maximum power of $5 \mathrm{~kW}$, was specifically designed to study the characteristics of fast neutron reactor cores. Each experimental core consists of tubes of square section filled by hand with 


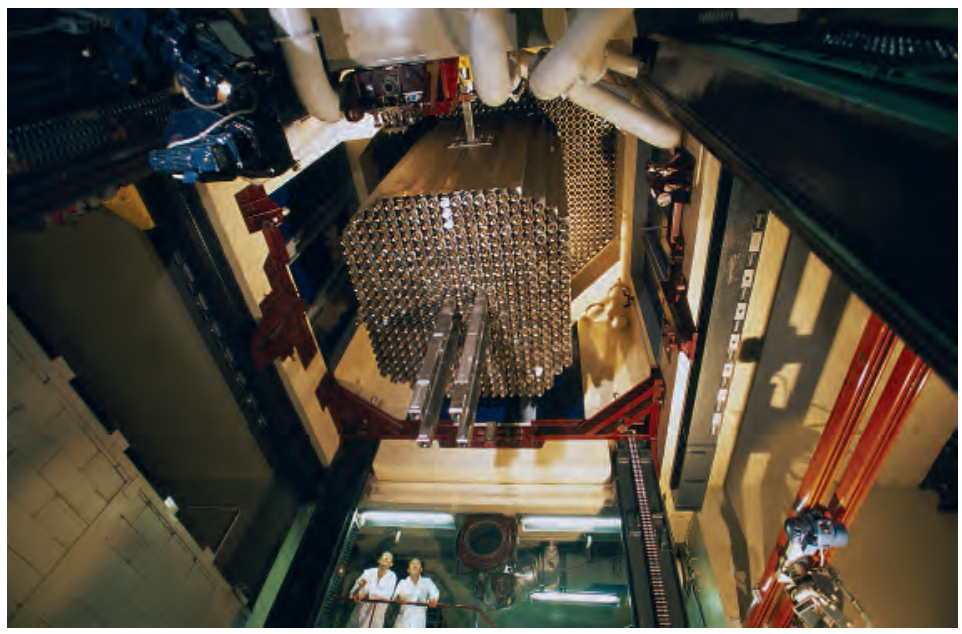

Figure 5.6. MASURCA reactor: core viewed from below, fuel elements being dropped. ( ) P. Stroppa/ CEA.

small fuel elements (in the form of rodlets or platelets), neutron-absorbing elements or coolant elements (sodium in solid form) representing the lattice to be studied from a neutronics point of view. The ability to create "à la carte" cores means that core concepts for very varied and innovative reactors, such as accelerator driven systems (ADS) and high temperature reactors (HTR), can be studied. The MASURCA assembly has been shut down since 2007 and the CEA is going to carry out major renovation work on it to answer neutronics questions related to the Generation IV fast neutron reactors, particularly for the ASTRID (Advanced Sodium Technological Reactor for Industrial Demonstration) project.

Whereas the MASURCA reactor has been kept in operation mainly to support studies related to the ASTRID project, experiments in the EOLE and MINERVE reactors were stopped at the end of 2017; there are plans to build a facility named ZEPHYR to replace them.

The low power research reactors also include reactors used for teaching. They are valuable for delivering the teaching programmes of educational establishments specializing in nuclear, as well as the training programmes of nuclear operators and safety bodies. Within these programmes, the reactors used are either reactors dedicated almost exclusively to training (the ISIS reactor at Saclay), or reactors that have training periods included in their operation (MINERVE reactor at Cadarache).

The ISIS reactor (figure 5.7) was designed as a neutron mockup of the OSIRIS reactor at a scale of 1:10. It has a maximum power of $700 \mathrm{~kW}$ and can be used to carry out tests related to new configurations of the OSIRIS core and new fuels or new irradiation experiments in the reactor. The ISIS reactor underwent major renovation work between 2004 and 2006 in order to adapt it fully for training activities. In particular, the control room was redesigned to accommodate participants in training sessions. A supervision 

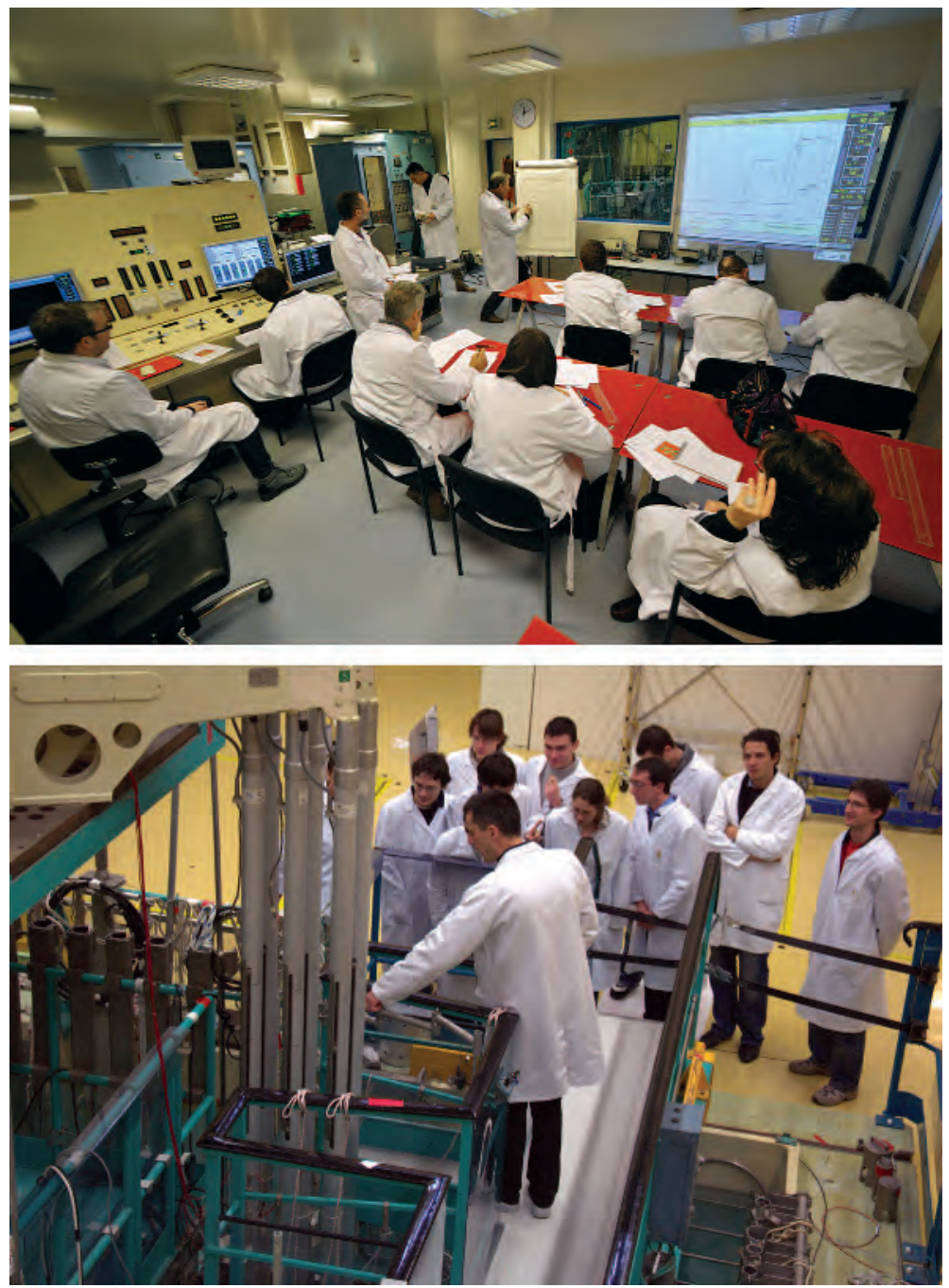

Figure 5.7. Top, French Master's course, practical work in the ISIS reactor control room (2013). () PF. Grosjean/CEA. Bottom, practical work in the ISIS reactor; students from the École des Ponts et Chaussées on the "Principles and operations on nuclear reactors" course (2010). ๑ S. Renard/CEA.

software was developed for monitoring changes to significant parameters during handling operations in the reactor. Around a hundred half-day practical training sessions are carried out each year at this facility, which is now assigned solely to training; its shutdown is scheduled for 2018.

For material testing, France particularly made use (until 2015) of the OSIRIS reactor at Saclay. The corresponding activities will be taken over by the Jules Horowitz 
reactor, which is under construction at Cadarache but is not expected to be commissioned until $2020^{107}$.

As a reminder, material testing reactors are designed to produce relatively high neutron fluxes and to accommodate devices inside the reactor core or around the edge of it, in which to place the items to be irradiated.

The OSIRIS reactor (figure 5.8), commissioned in 1966, was an open core pool-type reactor. The water acted simultaneously as moderator ${ }^{108}$, as coolant ${ }^{109}$, and as radiological shielding. Its core, which was fairly small $(57 \mathrm{~cm} \times 57 \mathrm{~cm} \times 60 \mathrm{~cm})$, contained 44 fuel elements and could release a maximum power of $70 \mathrm{MW}$. The water circulated from bottom to top in the core. The high neutron fluxes, both inside the core and around it, were greater than those in a PWR power reactor, making it possible to study

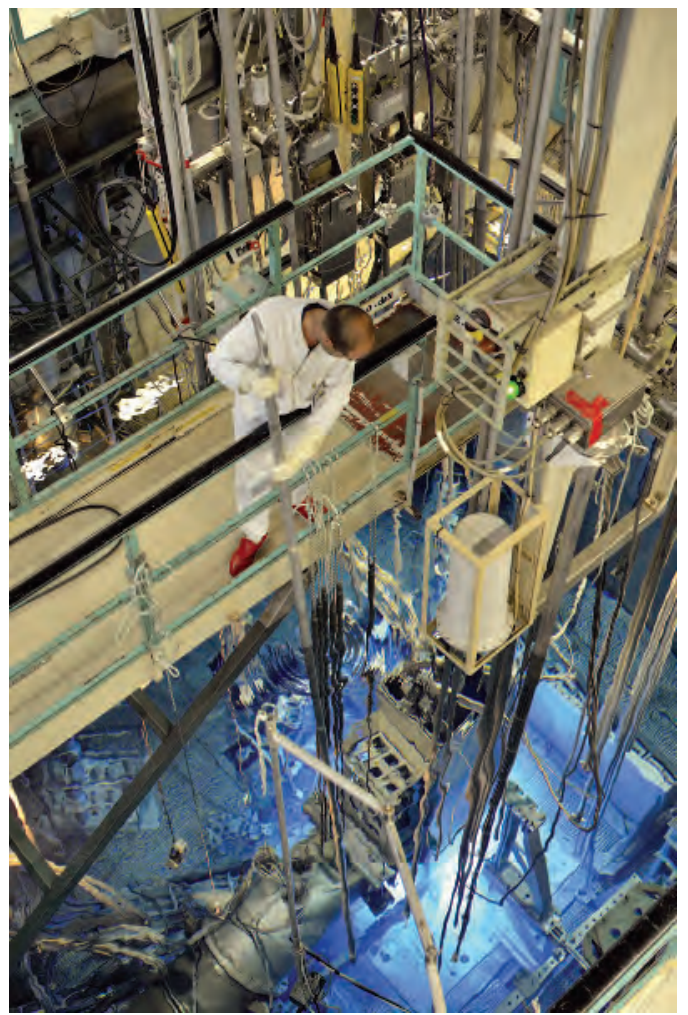

Figure 5.8. OSIRIS reactor pool. (c) Laurent Zylberman/Graphix-Images/IRSN.

107. "Le chantier du réacteur Jules Horowitz", Libération $\left\{\right.$ Sciences $\left.^{2}\right\}, 25$ January 2016.

108. A moderator is a material that slows down neutrons through a succession of collisions with atoms (generally hydrogen) present in the material.

109. A coolant absorbs and removes the heat produced in the fuel by the fission reactions. 
the accelerated ageing of materials under irradiation in these reactors. They could also be used to produce artificial radioisotopes used in medicine for diagnosis by scintigraphy or for treating certain cancers (brachytherapy) and other diseases. Also, the irradiation of monocrystalline silicon ingots made it possible to alter the atomic structure of the silicon, giving it the properties of a semiconductor (silicon "doped" in this way is used by the electronics industry).

\section{A new generation material testing reactor: the Jules Horowitz reactor}

The Jules Horowitz reactor ${ }^{110}$, or JHR, for which the design process was begun by the CEA in 1998, should meet the need expressed by the European Commission for a modern, flexible research facility (the other European reactors that can perform the same functions date from the 1960s, see table 5.2 below) to carry out experiments around twenty at once - contributing to:

- improving the competitiveness and service life of nuclear power reactors in operation,

- developing the performance of nuclear fuels in "third-generation" reactors such as the EPR (European Pressurized Reactor ${ }^{111}$ ),

- developing new materials and fuels for "fourth generation" (Gen IV) reactors such as the one for the ASTRID project,

- improving the reliability of European radioisotope supplies for the medical sector.

Table 5.2. Material testing reactors in Europe (source CEA).

\begin{tabular}{|l|c|c|c|}
\hline Country & Research reactor & Age (in 2017) & Power (MWth) \\
\hline Belgium & BR2, Mol & 54 & 60 \\
\hline Netherlands & HFR, Petten & 56 & 45 \\
\hline Norway & HRP, Halden & 57 & 19 \\
\hline France & OSIRIS & Shut down in 2015 after 49 years in operation & 70 \\
\hline Sweden & R2, Studsvik & Shut down in 2005 after 45 years in operation & 50 \\
\hline
\end{tabular}

Within the JHR project, the CEA is working with Belgian, Czech, Spanish, Finnish and Japanese research institutes and the companies EDF and AREVA (Framatome) in France and Vattenfall in Sweden. In 2008, India's Department of Atomic Energy (DAE) joined

110. Sources used: Nuclear Research Reactors, a Nuclear Energy Division monograph - 2012, pages 95 to 106, The JHR, CEA Cadarache website (http://www.cea.fr/english/Pages/researchareas/nuclear-energy/jules-horowitz-research-reactor-JHR.aspx ), which in particular links to the report published on the ASN's website "Réacteur Jules Horowitz - Évaluation complémentaire de la sûreté au regard de l'accident survenu à la centrale nucléaire de Fukushima I" (CEA/DEN/CAD/ DIR/CSN DO 575 13/09/11), the Wikipedia article and its references, etc.

111. European version of a pressurized water reactor. 
the seven original partners in the project. The agreements signed between these partners will give them access to the facility to conduct their own experiments.

The objective of the promoters of the JHR project is to create a major European infrastructure open to international collaboration that will help to cover research and development needs over several decades.

The JHR is a closed core pool-type reactor. The core will be composed of fuel elements of circular cross-section, with curved fuel plates, cooled by water streaming in an upward direction (primary coolant system). This assembly will be surrounded by reflector elements (water and beryllium) and will be placed in a pool. In terms of performance, its maximum power will be $100 \mathrm{MW}$ and the aim is to achieve a neutron flux of around $10^{15}$ neutrons. $\mathrm{cm}^{-2} \cdot \mathrm{s}^{-1}$ (energy greater than $0.1 \mathrm{MeV}$ ), with a fast neutron flux of energy greater than $1 \mathrm{MeV}$ of around $5 \times 10^{14}$ neutrons. $\mathrm{cm}^{-2} \cdot \mathrm{s}^{-1}$. A particular feature of the neutron spectrum is that it will have two energy peaks, enabling material testing to be carried out in the thermal neutron range (applications for common existing reactors) and partially in the fast neutron range (applications for Gen IV fast neutron reactors ${ }^{112}$ ).

Irradiation devices can be inserted in the centre of fuel elements (see diagram at the bottom of figure 5.10), can be positioned in place of fuel elements, or can be placed in the reflector (figure 5.9). Displacement systems in the core periphery can also be used to simulate conditions representative of transients, incidents or accidents likely to occur particularly in power reactors (slow power ramps).

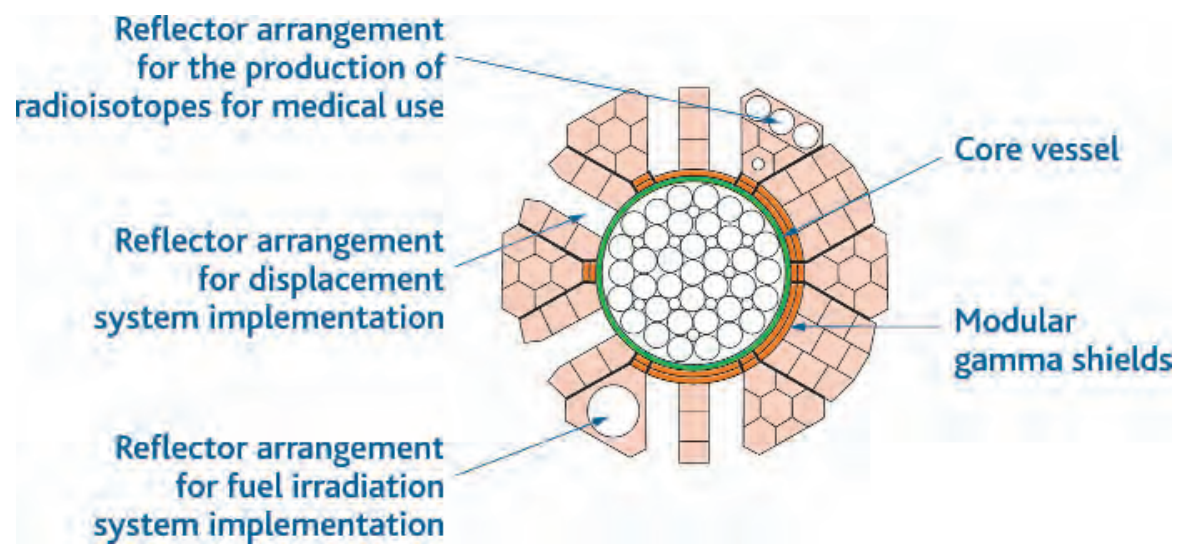

Figure 5.9. Planned layouts in the reflector area of the Jules Horowitz reactor. ๑ Georges Goué/IRSN.

Most of the samples that will be placed in the JHR core will be prepared and analysed in the fuel laboratories at the CEA centre at Cadarache, located close to the JHR to reduce the transport of radioactive materials (and the associated risks).

112. See the publication "Overview of Generation IV (Gen IV) Reactor Designs/Safety and Radiological Protection Considerations", Reference Documents Series, IRSN 2012/158, available at www.irsn.fr/EN. 


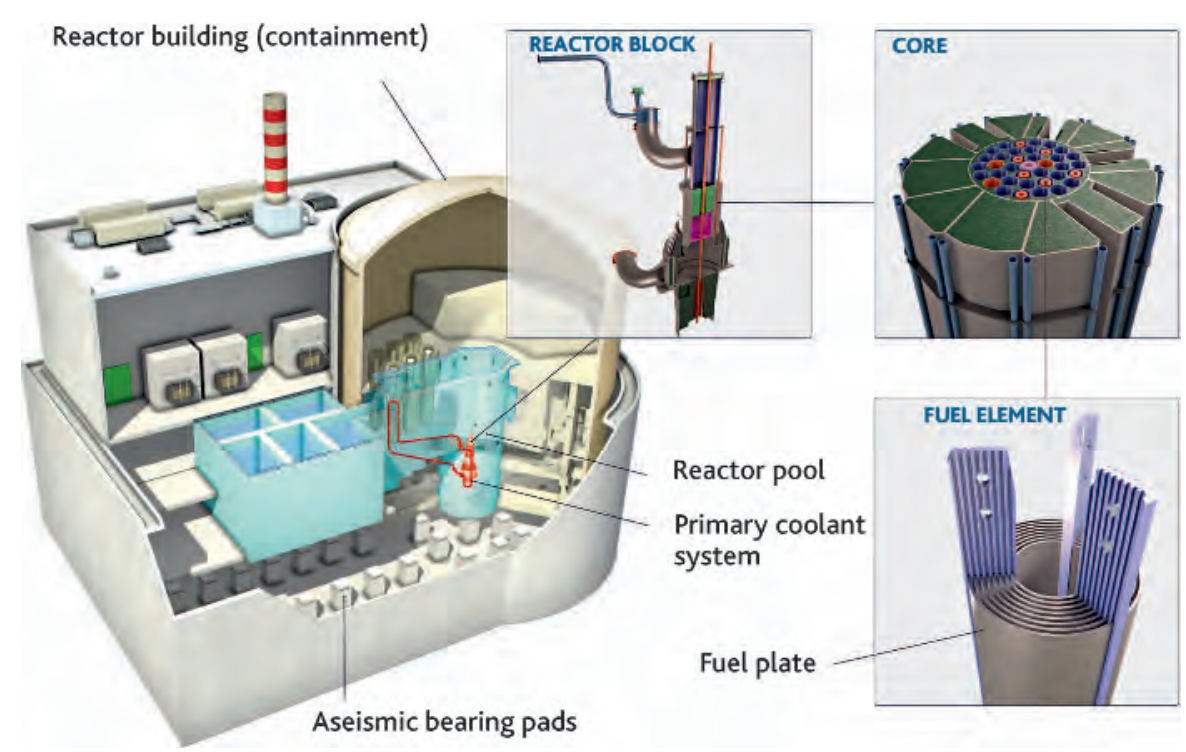

Figure 5.10. Jules Horowitz Reactor: diagrams of the nuclear unit, reactor block, core and a fuel element. (c) ASN.

It is expected that the JHR will contribute $25 \%$ of European radioisotope production for medical use, or even up to $50 \%$ if necessary. Since the OSIRIS reactor was shut down, technetium $-99^{\mathrm{m}}$ has been produced particularly at the HFR research reactor in Petten (Netherlands) and at the BR2 research reactor in Mol (Belgium) - the Canadian NRU reactor dating from 1957, which is responsible for more than $40 \%$ of global production, is back in operation after various shutdowns, particularly following the discovery in $\mathbf{2 0 0 9}$ of a heavy water leak at the base of the reactor vessel.

In terms of general architecture, the JHR consists of two buildings (see figure 5.10):

- the reactor building, which houses the reactor itself, the equipment needed to operate it, and the equipment used to monitor experiments (workstations for experimenters, electrical equipment, instrumentation and control equipment, etc.);

- the nuclear auxiliary building, which contains hot cells for preparing, conditioning and examining experimental samples, and three storage pools.

Both buildings will be on the same foundation raft; they constitute the "nuclear unit". Seismic isolation is achieved by means of aseismic bearing pads. This will be explained in more detail in section 7.4.2.

The reactor has three systems:

- the primary coolant system, which cools the reactor core through the circulation of pressurized water (at about 10 bars at the core inlet). This closed circuit is inside the reactor building. The reactor core and part of the primary system are submerged in the reactor pool (figure 5.11); 

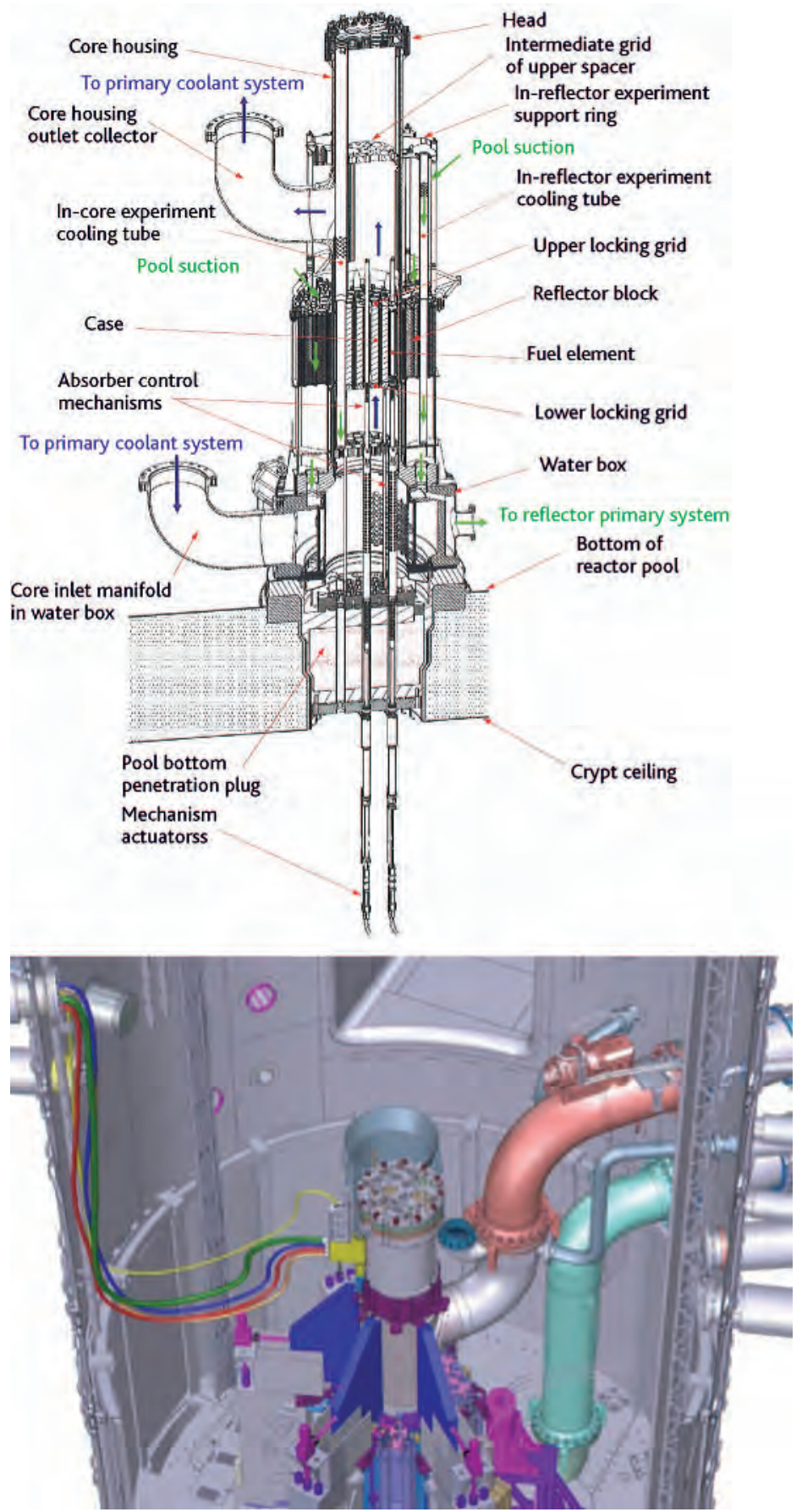

Figure 5.11. Reactor block of the JHR. @ DR. 
- the secondary coolant system, which is isolated from the primary system and cools the primary system by means of heat exchangers placed between the two systems in the reactor building. The pressure in the secondary system is higher than the pressure in the primary system so that, if there is a leak between the primary and secondary systems, the secondary system is not contaminated;

- an external coolant system, which cools the water in the secondary system by means of other heat exchangers placed in another building at the facility (the coolant building). This system will be connected by a channel to the Canal de Provence. The water will be returned to the EDF canal, ensuring that the water in the canal remains below a temperature of $25^{\circ} \mathrm{C}$, in accordance with regulations.

These three systems in series will reduce the risk of contamination being transferred from the core to the environment (the water in the EDF canal).

The JHR facility has three storage pools:

- the spent fuel storage pool, which will be used to store spent fuel from the reactor before it is processed at the Cogema plant at La Hague;

- the irradiated devices storage pool, which will be used to store (around thirty) experimental devices and to perform examinations under water;

- the irradiated components storage and dismantling pool, which will be used to store components from the reactor's internal structures, core structures (reflector) and tools used for handling and dismantling.

The fuel elements and experimental devices will be transferred between the reactor and the pools or hot cells under water.

The general safety objectives used for the design of the JHR, in terms of radiological consequences of incidents and accidents, are similar to those used for new generation power reactors such as the EPR; this will be discussed in more detail in chapter 7.

The gaseous discharges associated with the JHR will be generated mainly when experimental devices are opened in the hot cells and when degassing the primary circuit. The ventilation systems will be fitted with HEPA filters and iodine filters to limit the quantity of gaseous discharges. The activity of these discharges - consisting mainly of noble gases (xenon, krypton, etc.), halogens (iodine, etc.) and tritium - is expected to be similar to the activity measured at existing research reactors, considering the experiments conducted there.

Liquid waste should be generated mainly during experiments, decontamination of the hot cells, and regeneration of the resins used to purify the water in the reactor pool and the storage pools. These radioactive effluents will be managed by the treatment plant at the Cadarache Centre.

According to CEA estimations, when the JHR is in operation, gaseous discharges and liquid waste from the Cadarache Centre should remain at a few percent of the values stipulated by the annual authorizations for the Centre. 
The construction licence for the JHR was granted by decree ${ }^{113}$ in 2009 (it is not expected to be commissioned until 2020).

Among its reactors in operation, France also has two reactors delivering neutron beams used for scientific research. They are the ORPHEE reactor, operated by the CEA at Saclay ${ }^{114}$, and the high flux reactor (RHF), operated by the Institut Laue-Langevin at Grenoble.

These reactors operate in cycles of several weeks, separated by shutdowns for refuelling and maintenance. In these reactors, heavy water is used to slow the neutrons produced by fission (neutron moderation) and make them usable for testing matter:

- in the RHF reactor, heavy water is used as the core coolant (the core consists of a single fuel element), placed in a heavy water vessel, with the whole assembly sitting in a light water pool;

- in the ORPHEE reactor, light water is used as the core coolant and heavy water is used as the reflector, with the whole assembly sitting in a light water pool (see figure 5.12).
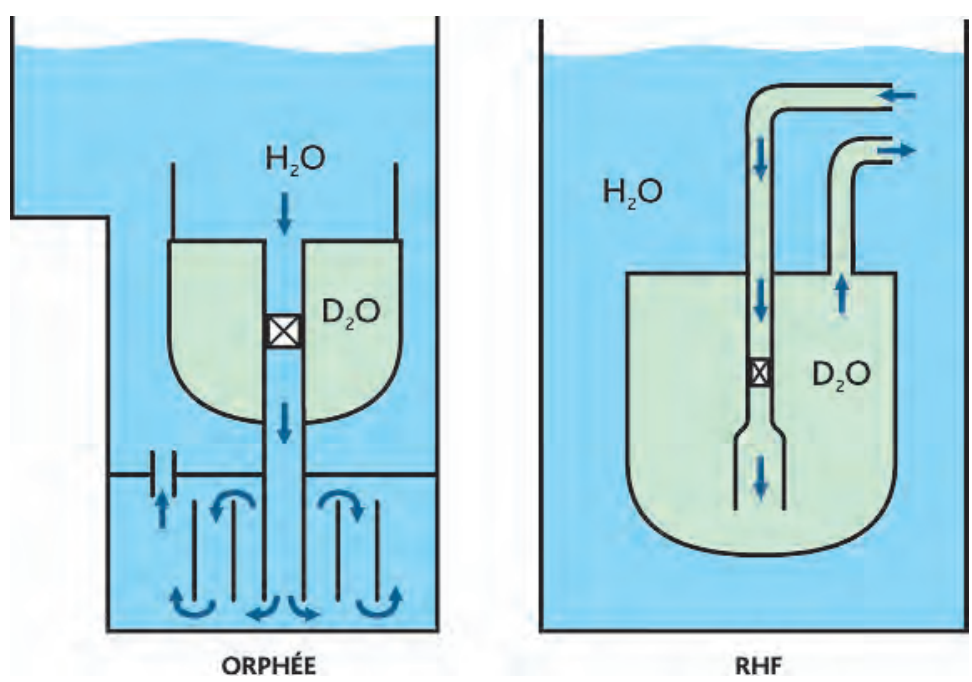

Figure 5.12. Respective uses of light water and heavy water in the ORPHEE and RHF reactors. In both cases, the water circulates downwards in the core. (C) Georges Goué/IRSN.

Because the energy of the neutrons must be controlled to suit the experiments being conducted, special devices are used to modify this energy locally. A container

113. Decree No 2009-1219 of 12 October 2009.

114. The corresponding basic nuclear installation (INB $\left.N^{\circ} 101\right)$ consists of the ORPHEE reactor and the Laboratoire Léon Brillouin (LBB) where researchers from the CNRS and the CEA work in the field of neutron spectrometry. 
filled with hydrogen or liquid deuterium (at a temperature of around $-250^{\circ} \mathrm{C}$ ) is used to obtain slow neutrons ("cold source ${ }^{115 ")}$ ) and a block of graphite heated to more than $1,000^{\circ} \mathrm{C}$ is used to obtain high energy neutrons ("hot source").

The neutrons (thermal, slow or fast) are "collected" for experimental use via "beam tube ends" directed at the reactor core. The collected neutrons are then guided out of the pool where they are filtered to extract the neutrons with the correct wavelength for irradiation of the material sample being tested (in the experimental area or neutron guide hall around the reactor - figure 5.13). The other neutrons in the beam are stopped by a concrete wall which acts as a shield.
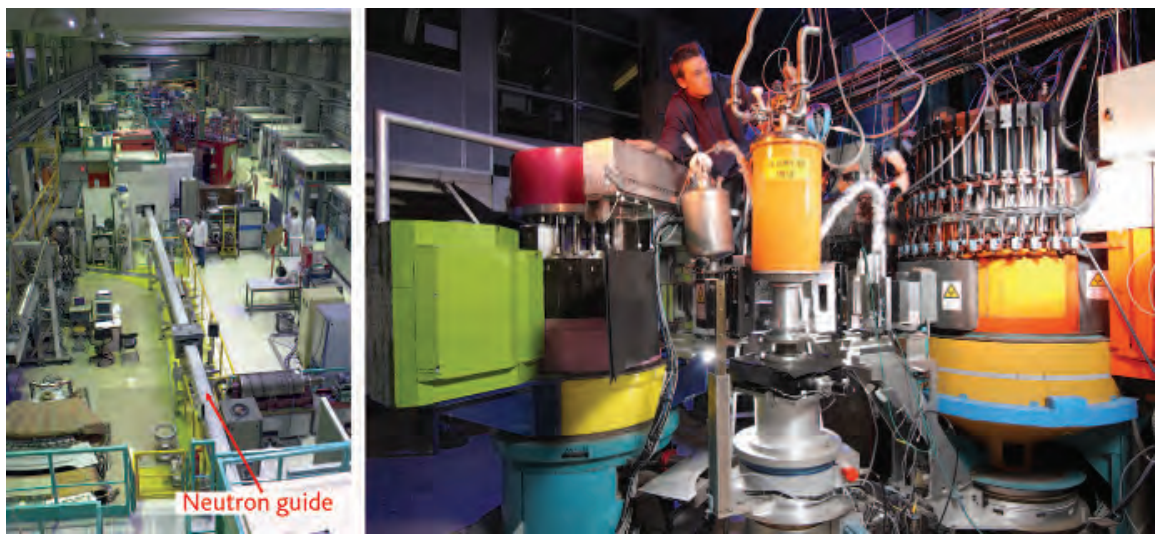

Figure 5.13. Left, a neutron guide hall (RHF). (C) Artechnique/ILL; right, "D10" device. @ ILL.

These reactors also have vertical channels near the heavy water vessel, used mainly for irradiation.

The ORPHEE reactor has nine horizontal (multiple beam) beam tubes at a tangent to the core, which enable 20 neutron beams to be used (figure 5.14). The beam tube ends are in the moderator (heavy water) near the core, where the heated neutron flux is at its greatest; three beam tube ends are directed at two "cold sources", and two others at one "hot source". The physicists doing research at ORPHEE belong to a laboratory run jointly by the CEA and the CNRS, known as the Laboratoire Léon Brillouin (LLB), and work in fields as varied as chemistry, biology, metallurgy and physics. The ORPHEE reactor is also used for activation analyses in partnership with the Laboratoire Pierre Süe (CEA), for irradiating samples and for producing radioisotopes for industrial and medical use (Cis-bio international), and finally for doping monocrystalline silicon by nuclear transmutation.

With a maximum power of $14 \mathrm{MW}$, the ORPHEE reactor (figure 5.15) delivers a neutron flux of up to $3 \times 10^{14}$ neutrons. $\mathrm{cm}^{-2} . \mathrm{s}^{-1}$ in the heavy water vessel. Its core, which consists of eight fuel elements of square cross-section, with flat fuel plates, containing

115. Not to be confused with the external source of cooling of a reactor (water from a river, the sea, air, etc.). 


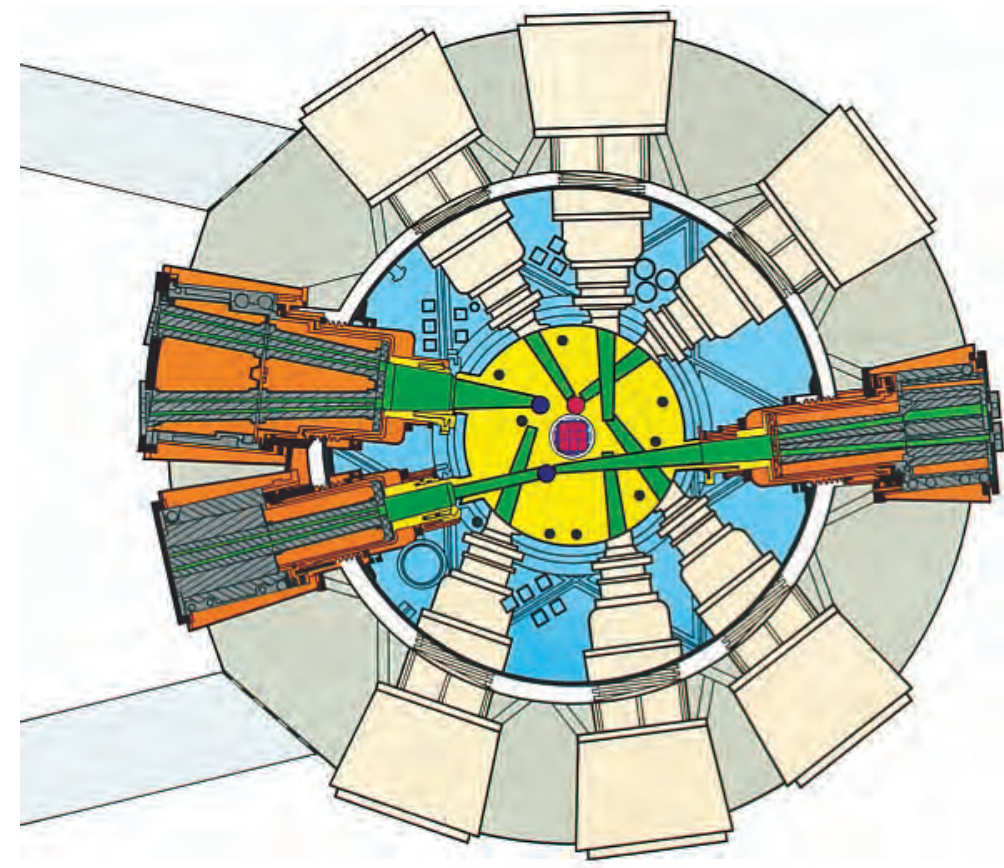

Figure 5.14. Horizontal cross-section of the ORPHEE reactor showing the nine beam tubes of the neutron channels. At the centre of the core, the red spots indicate the "cold sources" and the "hot source"; the heavy water is represented in yellow and the light water in blue. () CEA.

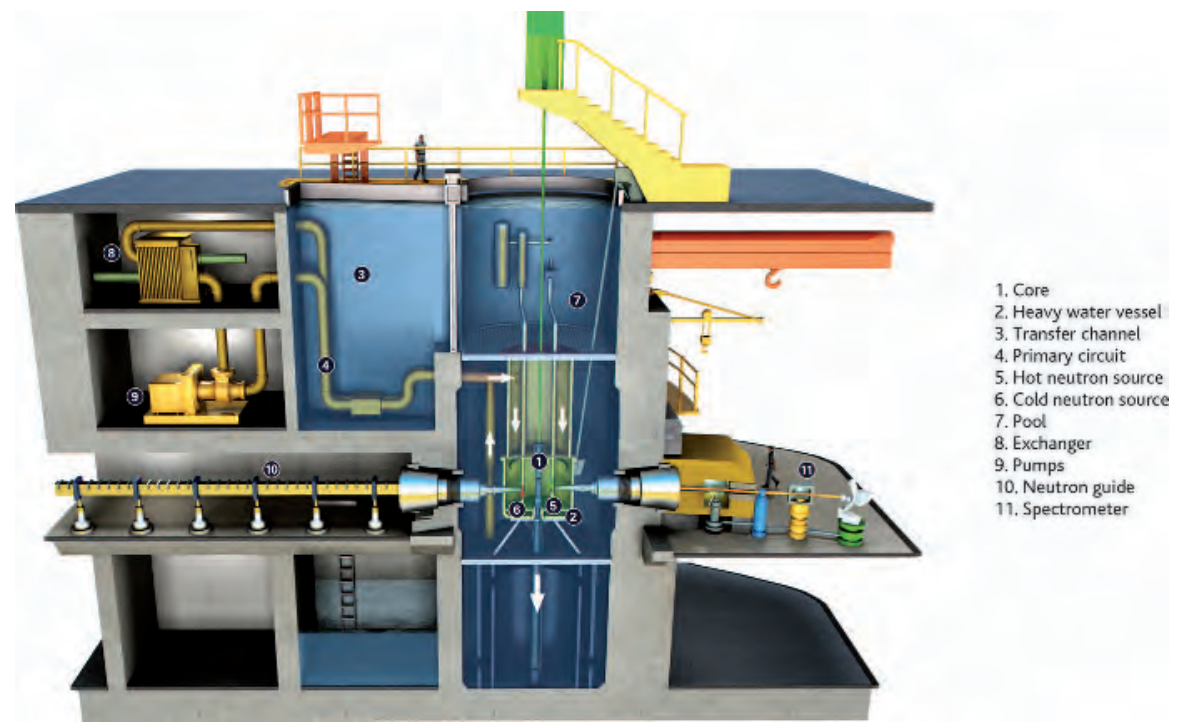

Figure 5.15. ORPHEE reactor: diagram of the reactor block, vertical section. ๑ CEA. 
highly enriched uranium (93\%), is cooled by light water circulating at a rate of $7.5 \mathrm{~m} / \mathrm{s}$. The assembly consisting of the reactor core and the heavy water vessel (made from stainless steel) is submerged in a light water pool.

The high flux reactor at Grenoble (RHF, figure 5.16), an international research facility, has 13 horizontal beam tubes, four inclined tubes and two vertical tubes (one of which is used for the startup neutron source). It can simultaneously deliver neutrons to around forty different experimental devices. Nine beam tubes are directed at two "cold sources" and four beam tubes are directed at the "hot source". The core of the RHF consists of a single annular fuel element containing curved fuel plates of highly enriched uranium (93\% of uranium-235). It is cooled with heavy water circulating at a rate of $5.5 \mathrm{~m} / \mathrm{s}$. It produces most intense neutron flux to date, of $1.5 \times 10^{15}$ neutrons. $\mathrm{cm}^{-2} . \mathrm{s}^{-1}$ (thermal neutron flux in the heavy water vessel). As with ORPHEE, the assembly consisting of the reactor core and the heavy water vessel (made from an aluminium alloy known as AG3NET in the case of the RHF) sit in a light water pool.

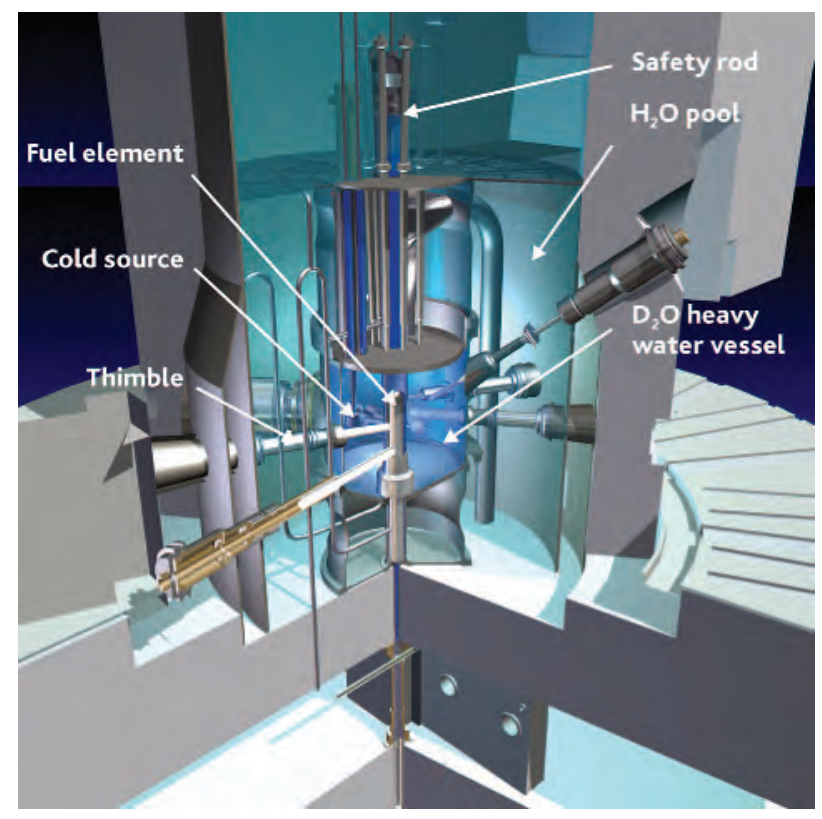

Figure 5.16. Diagram of the RHF. (C) ILL.

The heavy water detritiation facility, which used to be near the ILL, has been permanently shut down, so the operator has decided to contract out the detritiation of the heavy water to a Canadian company.

In 2016 France was still operating a research reactor dedicated entirely to safety testing, or more precisely to studying the behaviour of the fuel elements of light water nuclear power plants in certain accident situations. This was the CABRI reactor (figure 5.17), located at the CEA's Cadarache centre, which can be used to test a fresh or irradiated nuclear fuel sample under the conditions which would result from a 


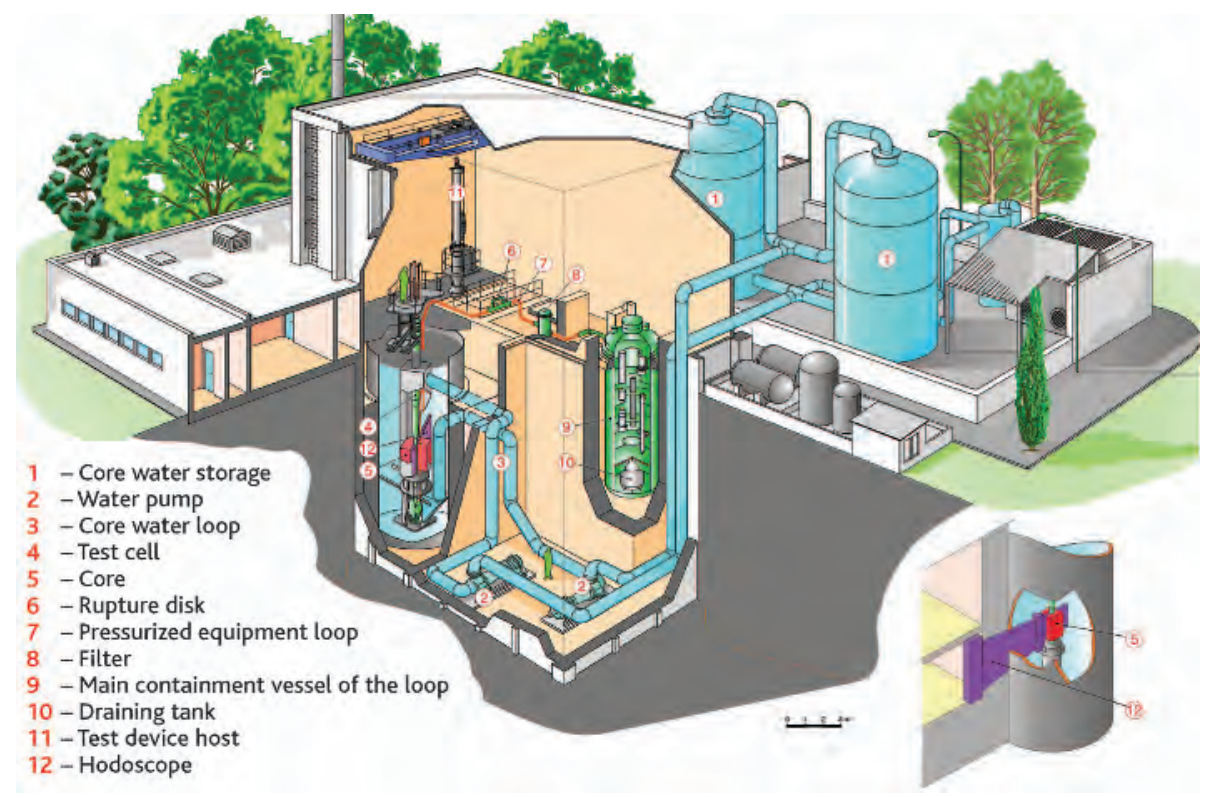

Figure 5.17. Diagram of the CABRI and its pressurized water test loop. @ DPAM/IRSN.

reactivity-initiated accident in a power reactor. The reactor consists of a driver core and an experimental loop. The part of the loop in the centre of the driver core holds the test device containing the fuel to be tested. The driver core supplies the neutron flux necessary to obtain the desired power in the fuel being tested, and the experimental loop makes it possible to apply thermohydraulic conditions representative of the conditions in a power reactor. A particular feature of this reactor is its controlled reactivity injection system. Instead of the last ring of fuel rods, four assemblies in the driver core are equipped with peripheral cylindrical tubes ${ }^{116}$, which are filled with pressurized helium-3 before the reactor is started (this gas is a good neutron-absorber). Once the reactor has reached nominal power and the required thermohydraulic conditions are obtained in the experimental loop, these tubes are depressurized by opening some valves in a specific sequence, which alters the reactivity ${ }^{117}$ and therefore the power delivered by the driver core. To study very rapid reactivity injections, it is possible to increase the power of the CABRI reactor from $100 \mathrm{~kW}$ to $20 \mathrm{GW}$ in a few milliseconds; the power then drops again as rapidly as it increased due to neutron feedback (in particular the Doppler effect).

In the past, the CABRI reactor had had a sodium loop, which was used for a number of different programmes until the $2000 \mathrm{~s}$ - not just for sodium-cooled fast neutron reactors but also for pressurized water reactors (REP-Na tests). This sodium loop was replaced by a pressurized water loop.

116. Also known as "transient rods".

117. As the gas disappears from the core, the number of neutrons in the core increases, causing more fissions. 
\#FOCUS.

\section{Some safety issues of nuclear power reactors explored with experimental programmes conducted at French research reactors}

Research reactors are essential tools for scientific and technological research and for supporting the development of nuclear power reactors. The experiments conducted in these reactors have helped to improve the safety of power reactors as regards accidents, through better knowledge of the phenomena involved.

The OSIRIS reactor has been used to study the behaviour of fuel cladding in pressurized water reactors subject to a slow pressure increase (slow power ramps of several tens of seconds to several minutes). These tests were carried out on sections of irradiated fuel rods and were used to establish limits for the use of different cladding materials.

Test programmes run at the CABRI reactor have studied the behaviour of fuel elements in power reactors in the event of the removal or ejection of neutronabsorbing elements from the cores of these reactors ${ }^{118}$.

From 1978 to 2001, the CABRI a reactor was used to study accidents involving inadvertent control rod withdrawal in sodium-cooled fast neutron reactors (SFRs), through (slow power ramp) tests conducted on single fuel pins ${ }^{119}$ in a sodium-filled loop. In particular, the risk of ejection of molten fuel from a pin with a pre-existing cladding defect was explored.

The SCARABEE reactor was also used from 1983 to 1989 to study, in a sodium loop of larger diameter than the CABRI loop, hypothetical accidents involving the blockage or melting of fuel assemblies in an SFR. The tests were conducted on small assemblies of up to 37 pins.

The sodium loop in the CABRI reactor was also used to study the behaviour of fuel rods in pressurized water reactors (PWRs) under neutron-absorbing rod cluster control assembly ejection conditions. This type of accident assumes that the cluster mechanism has ruptured. Ejection is caused by the pressure difference between the reactor coolant system and the containment vessel. This violent ejection causes a local runaway effect in the nuclear reaction for several tens of milliseconds (power pulse), leading to a rapid increase in fuel temperature. Neutron feedback limits the power transient before reactor scram, which occurs in a second phase. The sudden heating of the fuel pellets during the power pulse causes them to expand rapidly and, in some cases, to release the fission gases in the fuel. Subject to these stresses, the rod cladding can break up, releasing extremely hot fuel

118. See the publication "Current State of Research on Pressurized Water Reactor Safety", Science and Technology Series, IRSN/EDP Sciences, 2017.

119. Term used for SFRs. For PWRs, the term "rod" is used. 
fragments. For pressurized water reactors, criteria were set in the 1970 s based on the results of the SPERT tests ${ }^{120}$ conducted in the USA on fresh or lightly irradiated fuel. The tests conducted in the CABRI reactor in the 1990s (and at the NSRR reactor in Japan) on sections of industrial fuel rod pre-irradiated in pressurized water reactors studied the mechanical phenomena that occur during the first tens of milliseconds of the power excursion, when the cladding temperature is not really affected. These were known as the REP-Na tests, and in particular they included a test on MOX fuel ${ }^{121}$ that had reached a burnup of $55 \mathrm{GWd} / \mathrm{tU}$, and a test with a rod clad with a new alloy known as M5 ${ }^{\circledR}$.

To study phenomena that occur after the first few milliseconds (drying and swelling of the cladding), and the consequences in terms of a pressure wave of any dispersion of fuel in the coolant, IRSN has planned further tests in the CABRI reactor's pressurized water loop - this is the OECD ${ }^{122} /$ NEA project known as the Cabri International Programme (CIP), conducted in partnership with EDF and many foreign safety organizations and companies.

The PHEBUS reactor has made a major contribution to the acquisition of knowledge about the physics of accidents that can lead to partial or total core melt in a PWR ${ }^{123}$. The international Phebus-FP programme (FP for fission products), run by IRSN, has made it possible to simulate core melt on a small scale. The main aim of this programme was to contribute to improving knowledge of the radioactive releases that can occur in the environment during this type of accident. Five tests were conducted for this purpose from 1993 to 2004 in an experimental device installed in the PHEBUS reactor. These tests aimed to reproduce the main physical phenomena that could govern core melt in a pressurized water reactor and the transfer of radioactive substances from the nuclear fuel into the containment vessel. The experimental device (figure 5.18), which was used to simulate the core, the reactor primary coolant syste and the containment vessel, consisted of an in-pile part, passing into the core of the PHEBUS reactor, and an out-of-pile part known as the "FP container". The fuel used in the experiment, which was first irradiated in a research reactor or power reactor, was inserted into the in-pile part of the device. More than 200 measurement sensors and around 100 sampling devices constituted the test instrumentation. Following operation of the PHEBUS reactor at power to recreate short-lived fission products such as iodine-131 in the test assembly, the power was reduced and cooling of the test assembly was stopped. The test fuel then heated up rapidly until it melted. The fission products released by the fuel cladding were then guided into the FP container. The experiments carried out provided important data for understanding the mechanisms of core degradation in a PWR and the behaviour of the fission products released in the circuits. These tests also

120. SPERT (Special Power Excursion Reactor Test) is the name given to power excursion research reactors at the Idaho Falls research centre in the USA.

121. Mixed Oxide Fuel (mixed $\mathrm{UO}_{2}+\mathrm{PuO}_{2}$ fuel).

122. Organisation for Economic Co-operation and Development.

123. See the publication "Current State of Research on Pressurized Water Reactor Safety", Science and Technology Series, IRSN/EDP Sciences, 2017, and the publication "Nuclear Power Reactor Core Melt Accidents - Current State of Knowledge", Science and Technology Series, IRSN/EDP Sciences, 2013. 


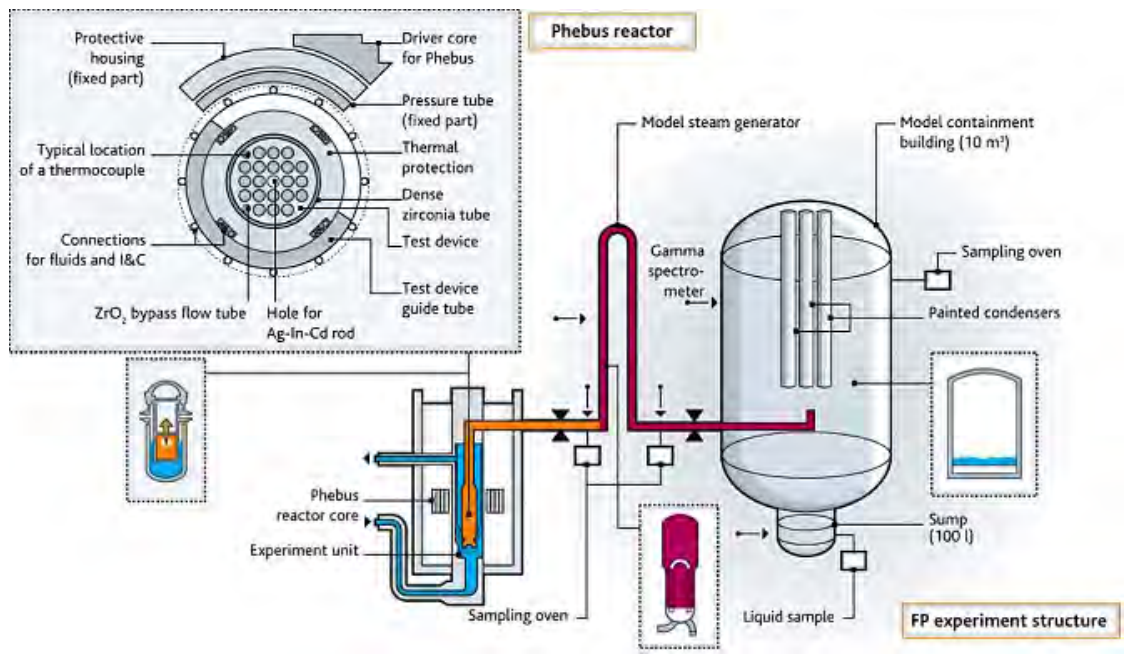

Figure 5.18. Diagram of the Phebus-FP facility. (C) Stéphane Jungers/IRSN -Source IRSN.

confirmed knowledge already acquired in laboratory experiments and helped to improve and validate several codes for simulating core melt accidents developed and used throughout the world, including some used by IRSN for its safety assessments or level 2 probabilistic safety analyses (ASTEC ${ }^{124}$ software).

124. Accident Source Term Evaluation Code (system of simulation codes for evaluating the physical phenomena occurring during a core melt accident in a pressurized water reactor). 